\title{
From OER to Open Pedagogy: Harnessing the Power of Open
}

\author{
Robin DeRosa* and Scott Robison
}

Plymouth State University

*rderosa@mail.plymouth.edu

\section{Editors' Commentary}

The unaffordability of education-whether in terms of tuition or textbooks-has undoubtedly made the 'free' element of Open a rallying cry. However, as the open education movement matures, the fulcrum of this discussion appears to be shifting from an emphasis on the adoption of open educational resources to an embrace of open educational practices. In this chapter, authors Robin DeRosa and Scott Robison draw on a variety of examples to illustrate the empowering potential of open pedagogy, an approach in which students are not just consumers of content but active and visible participants in the construction of knowledge. The chapter concludes with a reflection on some of the challenges and lessons learned from engaging students in public scholarship.

\section{Understanding the Value of Open}

There is no question that Open Educational Resources can save students money, and there is no question that the cost of higher education can be prohibitive for many students, so lowering costs is a shared imperative for those of us who are committed to educational access. But lowering costs always has to be contextualized into larger goals about learning. For example, a struggling university might curtail library hours or lower the heat in classrooms in order to save

How to cite this book chapter:

DeRosa, R and Robison S. 2017. From OER to Open Pedagogy: Harnessing the Power of Open. In: Jhangiani, R S and Biswas-Diener, R. (eds.) Open: The Philosophy and Practices that are Revolutionizing Education and Science. Pp. 115-124. London: Ubiquity Press. DOI: https://doi.org/10.5334/bbc.i. License: CC-BY 4.0 
money; these cost-saving measures could make education more accessible and could lower tuition and fees for students, but they could also impede learning. In this sense, cost savings is a complex issue, and any effort to save students money needs to be weighed against a range of repercussions distinct from the financial bottom line. The fact that learning materials now exist in digital formats does not necessarily mean that these learning materials can compete with traditional printed textbooks or other analog tools in terms of helping students learn. We have probably all tried some new-tech way of doing some old-tech process and found that the old-tech way worked better. So what about OER make them a good choice for adoption in the classroom? What, aside from cost-savings, make them valuable to education?

OER are free, digital, easily shared learning materials. Though colleges will have to address hardware issues (it would be a mistake not to acknowledge that access to the online world has real costs, and that free materials can only be freely available when institutions assure provision for all students), the potential that OER have to lower skyrocketing textbook costs is promising. When you look at the majority of research and press about OER, they focus on the rising costs of textbooks and the phenomenal cost-saving potential of OER. Individual students could save thousands of dollars over the course of an academic degree; colleges and universities could save hundreds of thousands - even millions - for their student bodies. In addition, institutions stand to strengthen their own financial health as they improve retention and enrollment rates by committing to OER initiatives. So should faculty convert to OER because it's cheaper for students? Or because it can improve the financial health of our institutions? Should we adopt OER simply because the technology is available? Or is something larger at stake here?

First, we need a corrective to the definition in the previous paragraph, since it's not enough to say that 'OER are free, digital, easily shared learning materials.' To be 'open' as well as free, educational materials must carry an open license (usually a Creative Commons license), meaning that OER can be reused, remixed, revised, redistributed, and retained. In other words, OER are flexible, and they empower faculty and students to work together to customize learning materials to suit specific courses and objectives. It's the way that the learning materials respond to learners and teachers that makes OER exciting; what should really galvanize faculty with an interest in educational transformation are the possibilities for pedagogical change that OER make explicit.

Student-centered pedagogy is clearly in fashion at the moment. But what does it mean to call an educational experience 'student-centered'? In many cases, people seem to conflate student-centered pedagogy with a customerservice model aimed at student satisfaction. Often, we hear 'student-centered' trotted out in policy discussions aimed at eliminating bureaucratic obstacles for students (for example, making transferring credits between institutions easier), or in faculty conversations about teaching methods. In the latter, faculty talk about increasing class discussion and refocusing classroom dynamics 
away from traditional lectures and toward a more interactive model. But in many cases, these new 'student-centered' policies do little more than respond to market demand, and these 'student-centered' pedagogies do little more than acknowledge a baseline student voice as part of the course. How can OER offer a more robust vision for centering our students in their educational experience?

By replacing a static textbook — or other stable learning material — with one that is openly licensed, faculty have the opportunity to create a new relationship between learners and the information they access in the course. Instead of thinking of knowledge as something students need to download into their brains, we start thinking of knowledge as something continuously created and revised. Whether students participate in the development and revision of OER or not, this redefined relationship between students and their course 'texts' is central to the philosophy of learning that the course espouses. If faculty involve their students in interacting with OER, this relationship becomes even more explicit, as students are expected to critique and contribute to the body of knowledge from which they are learning. In this sense, knowledge is less a product that has distinct beginning and end points and is instead a process in which students can engage, ideally beyond the bounds of the course.

If texts - content - are at the heart of a course, and content is now shaped into a process that depends on learner engagement in order to function fully, then OER propel us into truly student-centered territory. This territory might more aptly be described as 'learner-centered' or even 'learner-directed' if we follow through on the open pedagogy towards which OER gesture. (For the purposes of this inquiry, this article defines 'open pedagogy' in a way that remixes and revises the complex definition of 'critical digital pedagogy' set forth by Jesse Stommel.)

OER make possible the shift from a primarily student-content interaction to an arrangement where the content is integral to the student-student and student-instructor interactions as well. What we once thought of as pedagogical accompaniments to content (class discussion, students assignments, etc.) are now inextricable from the content itself, which has been set in motion as a process by the community that interacts with it. Moreover, students asked to interact with OER become part of a wider public of developers, much like an open-source community. We can capitalize on this relationship between enrolled students and a broader public by drawing in wider communities of learners and expertise to help our students find relevance in their work, situate their ideas into key contexts, and contribute to the public good. We can ask our students - and ourselves as faculty - not just to deliver excellence within a prescribed set of parameters, but to help develop those parameters by asking questions about what problems need to be solved, what ideas need to be explored, what new paths should be carved based on the diverse perspectives at the table. Open pedagogy uses OER as a jumping-off point for remaking our courses so that they become not just repositories for content, but platforms for learning, collaboration, and engagement with the world outside the classroom. 
To help explore how this theory can be put into practice, we will offer a few specific examples of how open pedagogy - in concert with OER or even distinct from it - can empower learners in a course.

\section{Wikipedia Assignments: an example of open scholarship}

According to Alexa Internet, Wikipedia is the sixth most-visited website in the United States. When the general public searches the internet for information, Wikipedia articles are generally at the top of the search results. The accuracy of the information on Wikipedia is dependent on the constant contributions, revisions and confirmations from diligent contributors. An article can receive 'Good Article' status by the Wikipedia community if it meets six criteria (well written, verifiable, broad in coverage, neutral, stable, and if possible, illustrated with images). At the time of this writing, of the nearly more than 5 million articles in English Wikipedia, only about 35,000 (>1\%) have achieved a Good Article status or better. Much work is yet to be done. The Wiki Education Foundation provides resources to help educators involve students in advancing access to knowledge while building their digital literacy skills. Their model involves an 'assignment' that replaces a more traditional research paper where the task is to write or edit and improve a Wikipedia article; perhaps attaining Good or even Featured Article status. Instead of writing solely for their instructor and a grade, they are writing for the public. This is vastly different than the disposable assignment where students' work (and feedback from the instructor) often end up in the class recycling bin at the end of the semester. Rather than only being 'graded' by an instructor, they may have to respond to other Wikipedia readers and reviewers. Have they written clearly enough for a general audience? Does their writing have a logical flow? Have they supported their statements properly and soundly? These are some of the questions and skills that Jon Beasley-Murray and his students at the University of British Columbia confronted when they worked on this kind of a project for a class called 'Murder, Madness, and Mayhem: Latin American Literature in Translation.' Their goals (all of which were attained) included improving Wikipedia's coverage of selected articles on Latin American literature, submitting these articles to Wikipedia review processes, and increasing the number of featured articles in this area. In Beasley-Murray's words:

'I decided to include wikipedia as a central part of a course I was teaching in the belief that it was only by actively contributing to the encyclopedia that they would learn about its weaknesses, and also its strengths. And also with the idea that they would thereby, and perhaps rather incidentally, improve articles in a field (Latin American literature) in which in my experience wikipedia has been especially weak.' 
'I liked the idea that students would be engaging in real world project, with tangible and public, if not necessarily permanent, effects. In the end, an essay or an exam is an instance of busywork: usually written in haste; for one particular reader, the professor; and thereafter discarded.'

'I'd like to think that it is teaching the students research skills and writing skills in what is very much a real world environment. They were set a medium-to long-term goal at the beginning of the semester, and were required to work collaboratively both within their own groups and with strangers in the public domain to plan how to achieve and deliver that goal. And their final product is to be a professional piece of work that will be viewed by many thousands of people, a resource that is in most cases the first port of call for future researchers, whether students like themselves or the any of the many millions from all over the world who visit wikipedia. Most of these articles are, after all, the top hit (or very close to it) in any internet search of the topic. By comparison, the usual essays and exams that we assign our students really are rather pointless busywork.'

To date, more than 22,000 students enrolled in $>1,000$ courses have participated in the Wikipedia assignments, collectively working on more than 37,000 articles. Professional bodies like the Association for Psychological Science and the American Sociological Association have called on their membership to participate in their own Wikipedia initiatives. These calls have been heeded, with faculty like Paula Marentette, Erik Olin Wright, and Martha Groom among the $97 \%$ of instructors who report that they would teach with Wikipedia again.

\section{Noba Project Student Video Awards: an example using video}

The use of video can be a highly effective way to communicate information. In 2011, Salman Khan of the Khan Academy urged educators to use video to 'reinvent education' by flipping instructor content online. An open pedagogy perspective invites students to be content creators. Willmott et al. (2012) found such learner-centered activities can inspire and motivate students when they are engaged with course content. The Noba Project (see Chapter 16) offers an annual competition in which students submit creative short videos which address one of Noba's suggested psychology topics or issues. The videos should help viewers understand and remember the concepts around the topic and must be three minutes or less. The US $\$ 10,000$ in prize money is distributed among the top videos each year. The 'products' that students create are impressive. The 2015 Noba Student Video Award projects are free and 'open' for review and reuse under a Creative Commons license. Not only does an experience like this engage and empower the students who create the content, but the content then becomes part of the learning process for future psychology students. 


\section{The Class-Created Textbook: An example from Robin's literature course}

In my English course on early American literature, I realized that students were paying close to US $\$ 100$ for a textbook filled with literature that was virtually all in the public domain. Of course, they were also paying for a host of helpful edits to that literature: spelling updates, excerpting decisions, explanatory annotations. One summer before I was going to teach the course again, I posted a call to alums of the course and asked if anyone wanted to help me track down public domain versions of the texts. About ten students were interested in working on the project, since the idea that they could build a replacement no-cost text for future generations of students in their program was appealing to them. By the end of the summer, we had a solid skeletal framework of texts assembled into an eBook that we built using PressBooks, a free user-friendly WordPress platform that makes it easy to create books and publish them online. When the course began, new students in the class took on editing duties: updating spelling; excerpting selected longer texts; and adding front matter for each chapter which included discussion questions and some interactive video. These were students with virtually no familiarity with early American literature, but they were able to do this work better than I could have, since they were essentially producing a collection targeted at their exact demographic. In addition, they felt remarkably more attached to their course textbook given the fact that they, in essence, were its authors. We have only taken one course of students through the book so far, and much of it is rough, but we share it openly and look forward to improving it every time a new group of learners engages with it and offers updates, corrections, and additions.

Part of what we realized was fun about the open textbook was the way that students in the course could do the work of real scholars, and the way that they could imagine a connection to future learners who would engage with their work. To capitalize on the sense of connection to a scholarly community (both senior and junior to them), I introduced a tool called Hypothes.is into the mix. Hypothes.is is a web annotation tool that allows readers of any website to annotate the text on that site, and these annotations can be public, allowing for other readers to reply and engage with the annotations. Our open textbook allowed us to share our text but also open conversations around that text, and represent our reading as something that was, in very visible ways, an act of participation in a scholarly community. Students loved it, and the whole process, from creating the OER to revising it with students to annotating it publicly, was catalyzed by the idea of the open textbook.

\section{The Crowd-Sourced Syllabus: An example from Robin's writing course}

Creating or adopting an open textbook can allow for exciting interactions between students, content, and broader academic and non-academic publics. But once we 
commit to student-directed learning, we can use open pedagogy to rethink our courses beyond the textbook, from the ground up, in ways that can ultimately make a student's experience in our class more meaningful. In my Composition course this semester, I started by asking students what they felt like they needed to learn. Together, we crafted our course objectives, just the way my American lit students had crafted our textbook. Some of the objectives they developed were predictably connected to writing, but others surprised me: for example, they wanted to add objectives about time management and about engaging with current events. From there, students crafted their own writing assignments and tied them to the course objectives. After that, we worked out a grading process that would allow them to self-grade using rubrics that we agreed on. Finally, all work would be done on their own public websites (their 'ePorts'), which they would build from scratch, control themselves, and take with them after the class ended. In effect, the course is centrally student-directed. It's also unfolding in public, in a kind of triangle between my website which contains our syllabus and readings, their ePorts where they do their work, and Twitter, where we chat together and share ideas with others who are interested. Obviously, this course is a fairly radical enacting of the principles of 'open pedagogy', and it is probably too extreme a model for many faculty in many courses, but it does show us that when begin to empower learners to engage with the course content in truly dialogic ways, we can envision new possibilities for every level of course design.

\section{Working in Public: Lessons and challenges on the ground}

While some students will surely long for the days where they could just open a textbook, memorize a list of facts, and recite that list on an assessment, most students seem truly thrilled to finally be participating in - rather than just absorbing - their educations. Of course, as teachers, we have to weigh this kind of student empowerment against the very real challenges of working in public in these ways. First of all, privacy concerns are not only legitimate, they are also sometimes a matter of life and death. One of our students had transferred to our university as part of an elaborate plan to go into hiding from her abusive boyfriend; there could have been deadly consequences had she used her real identity online. There are good ways that students can protect themselves while working in public, but often times the risks are different for different students, and instructors need to educate themselves about safety concerns, about big data and how it is used, and about how the tools they recommend protect or compromise student privacy.

In addition to safety and privacy, another challenge relates to the idea that students will be putting work into the public commons that might reflect poorly on them because it is not polished or sophisticated. This was very clear in Robin's Composition course, where students sometime struggled with basic literacy issues that made their online writing very rough. To us, this is less 
about a problem with the students or their work, and more about the way that the web has been underutilized as a workshop space. The reason that we changed the term for student websites from 'ePortfolio' to 'ePort' is that we wanted to de-emphasize the idea that only perfectly polished work belongs on the web, and instead suggest that the internet is far more powerful and helpful to us if we use it as portal through which we can communicate with others. We try to model this ourselves by sharing our work online before it is polished and complete, and we try to emphasize all writing and creation as an iterative, ongoing process that the web can facilitate. If they post work that is not perfect (and of course, they only post work that is not perfect), we all offer suggestions and comments - publicly - and they keep working to improve the piece. It is our belief that the 'future employers' that we are often fearful will penalize our students for their imperfect public work will overlook the imperfection in favor of the evidence of a student's ability to engage in the digital world for the benefit of improving their projects. But this is something we all have to do together: to change the web from a stale collection of rapidly-outdating artifacts of perfection to a living, growing collaborative space where new ideas are always developing.

\section{The Power of Open: A concluding thought}

If we think of OER as just free digital stuff, as products, we can surely lower costs for students; we might even help them pass more courses because they will have free, portable, and permanent access to their learning materials. But we largely miss out on the opportunity to empower our students, to help them see content as something they can curate and create, and to help them see themselves as contributing members to the public marketplace of ideas. Essentially, this is a move from thinking about OER as open textbooks and thinking about them as opening textbooks....and all sorts of other educational materials and processes. When we think about OER as something we do rather than something we find/ adopt/acquire, we begin to tap their full potential for learning.

\section{Previous publication}

A previous version of this chapter appeared in Educause Review on November 9, 2015 (CC-BY 4.0).

\section{References}

Amado, M., Ashton, K., Ashton, S., Bostwick, Nera, V., Nisse, T., Randall, D. (2015). Project management for instructional designers. Retrieved from http://pm4id.org/ 
American Sociological Association. (2016). American sociological association Wikipedia initiative. Retrieved from http://www.asanet.org/about/wiki_ Initiative.cfm

Association for Psychological Science. (2016). Wikipedia initiative. Retrieved from http://www.psychologicalscience.org/index.php/members/apswikipedia-initiative

Creative Commons. (2016). About the licenses. Retrieved from: https://creative commons.org/licenses/

Dean, J. (2015). Undergrad Shannon Griffiths on using hypothesis in the classroom. [Web log post]. Retrieved from https://hypothes.is/blog/undergradshannon-griffiths-on-using-hypothesis-in-the-classroom/

DeRosa, R. (2013). Open pedagogy [PowerPoint slides]. Retrieved from http:// www.slideshare.net/orbitdog1/open-pedagogy-for-elearning-pioneers

DeRosa, R. (2015). The open anthology of earlier American literature. Retrieved from http://openamlit.pressbooks.com/

DeRosa, R. (2016a). Composition. [Web log post]. Retrieved from http://robin derosa.net/composition-2/

DeRosa, R. (2016b). \#opencomp gets rolling: Students in an open-pedagogybased composition course. Retrieved from https://storify.com/actualham/ opencomp-gets-rolling

DeRosa, R., \& Robison, S. (2015). Pedagogy, technology, and the example of open educational resources. Educause Review. Retrieved from http:// er.educause.edu/articles/2015/11/pedagogy-technology-and-the-exampleof-open-educational-resources

Guess, A. (2007). When Wikipedia Is the assignment. Retrieved from https:// www.insidehighered.com/news/2007/10/29/wikipedia

Hypothes.is. (2016). Annotate with anyone, anywhere. Retrieved from https:// hypothes.is/

Jbmurray/Madness. (2016). Was introducing Wikipedia to the classroom an act of madness leading only to mayhem if not murder? Retrieved from https:// en.wikipedia.org/wiki/User:Jbmurray/Madness

Khan, S. (2011, March). Let's use video to reinvent education. [Video file]. Retrieved from http://www.ted.com/talks/salman_khan_let_s_use_video_ to_reinvent_education

Laurent, M. R., \& Vickers, T. J. (2009). Seeking health information online: Does Wikipedia matter? Journal of the American Medical Informatics Association, 16(4), 471-479. Retrieved from http://jamia.oxfordjournals.org/content/ $16 / 4 / 471$

Marentette, P. (2014). Achieving 'good article' status in Wikipedia. Observer, 27(3). Retrieved from http://www.psychologicalscience.org/index.php/ publications/observer/2014/march-14/achieving-good-article-status-inwikipedia.html

Noba Psychology. (2015). 2015 Noba student video award recipients. Retrieved from http://nobaproject.com/student-video-award/winners 
Noba Psychology. (2016). 2016/17 Noba + Psi Chi Student Video Award. Retrieved from http://nobaproject.com/student-video-award

Pawlyshyn, N., Braddlee, Casper, L., \& Miller, H. (2013). Adopting OER: A case study of cross-institutional collaboration and innovation. Retrieved from http://er.educause.edu/articles/2013/11/adopting-oer-a-case-study-ofcrossinstitutional-collaboration-and-innovation

Senack, E. (2015). Open Textbooks: The Billion-Dollar Solution. Retrieved from http://studentpirgs.org/sites/student/files/reports/The\%20Billion\%20 Dollar\%20Solution.pdf

Stommel, J. (2014). Critical digital pedagogy: A definition. Hybrid Pedagogy. Retrieved from http://www.digitalpedagogylab.com/hybridped/criticaldigital-pedagogy-definition/

The Wiki Education Foundation. (2016a). Inspiring learning. Enriching Wikipedia. Retrieved from https://wikiedu.org/

The Wiki Education Foundation. (2016b). How do you measure the difference that open knowledge makes? Retrieved from https://wikiedu.org/changing/ classrooms/

Whitman, W. (2015). Song of myself. In R. DeRosa (Ed.), The open education anthology of earlier American literature. Pressbooks. Retrieved from https:// via.hypothes.is/http://openamlit.pressbooks.com/chapter/song-of-myself/

Wikipedia. (2016a). Good article criteria. Retrieved from https://en.wikipedia. org/wiki/Wikipedia:Good_article_criteria

Wikipedia. (2016b). Wikipedia: WikiProject Murder Madness and Mayhem. Retrieved from https://en.wikipedia.org/wiki/Wikipedia:WikiProject_ Murder_Madness_and_Mayhem

Wikiwand. (2016). Alexa Internet. Retrieved from: https://www.wikiwand. com/en/Alexa_Internet

Wiley, D. (2013, October 21). What is open pedagogy? [Web log comment]. Retrieved from http://opencontent.org/blog/archives/2975

Willmot, P., Bramhall, M. \& Radley, K. (2012). Using digital video reporting to inspire and engage students. Retrieved from http://www.raeng.org.uk/ publications/other/using-digital-video-reporting

Wright, E. O. (2012). Writing Wikipedia Articles as a Classroom Assignment. Retrieved from https://www.ssc.wisc.edu/ wright/ASA/Writing\%20Wikipedia \%20Articles\%20as\%20a\%20Classroom\%20Assignment.pdf 